BMJ Open Sport \& Exercise Medicine

\title{
Lower medial hamstring activity after ACL reconstruction during running: a cross-sectional study
}

\author{
Einar Einarsson (D) , ${ }^{1,2}$ Athol Thomson, ${ }^{3}$ Bart Sas, ${ }^{1}$ CLint Hansen (D) , \\ Magnus Gislason, ${ }^{2}$ Rodney Whiteley ${ }^{3}$
}

To cite: Einarsson $\mathrm{E}$,

Thomson A, Sas B, et al. Lower medial hamstring activity after ACL reconstruction during running: a crosssectional study. BMJ Open Sport \& Exercise Medicine 2021;7:e000875. doi:10.1136/ bmjsem-2020-000875

Accepted 22 February 2021

\section{Check for updates}

(c) Author(s) (or their employer(s)) 2021. Re-use permitted under CC BY-NC. No commercial re-use. See rights and permissions. Published by BMJ.

${ }^{1}$ Rehabilitation, Aspetar Orthopaedic and Sports Medicine Hospital, Doha, Qatar ${ }^{2}$ Department of Engineering, University of Reykjavik, Reykjavik, Iceland

${ }^{3}$ Research \& Scientific Support, Aspetar Orthopaedic and Sports Medicine Hospital, Doha, Qatar ${ }^{4}$ Department of Neurology, Christian-Albrechts Universitat zu Kiel, Kiel, Deutschland, Germany

Correspondence to Einar Einarsson; einar.einarsson@aspetar.com

\section{ABSTRACT}

Objective Anterior cruciate ligament reconstruction (ACLR) predisposes footballers for subsequent ACL and hamstring (HS) injury. This case series examines HS muscle activation patterns during the running in ACLR patients (bone-patellar tendon-bone (BTB) and (HS) graft) after completion of functional criteria allowing return to training.

Methods Electromyography (EMG) recorded from medial and lateral HS bilaterally during treadmill running $(12,14$ and $16 \mathrm{~km} /$ hour) from 21 male ACLR patients on average 7 months from surgery (5-9) that underwent $(H S)(n=12)$ or BTB reconstruction $(n=9)$ were compared with 19 healthy runners. Main outcome measures: EMG signal was normalised to peak during the running. Pairwise comparisons were made for each muscle group examining stance and swing activation for mean and peak EMG for each patient group and leg.

Results Significantly lower relative peak activation in stance (not swing) phase for medial HS was seen for all conditions with effect sizes ranging from -0.63 (controls, BTB non-injured leg) to -1.09 (HS injured). For lateral HS only BTB injured were significantly lower in stance phase $(-1.05)$

Conclusion ACLR patients show neuromuscular alterations during different phases of running. The finding of reduced medial HS activity in stance phase might have implications for knee instability and HS muscle injury on resumption of sport.

\section{INTRODUCTION}

After anterior cruciate ligament reconstruction (ACLR) returning to sport at the same level and minimising risk of reinjury is complex. Eighty-three per cent of elite athletes return to sport, ${ }^{1}$ and at 3 years postACLR, only $65 \%$ of professional football players are still playing at same level. ${ }^{2}$ ACLR failure rates are documented to be between $2.8 \%-5 \%$ in international cohorts, ${ }^{34}$ and in athletes $5 \%-17 \% .^{156}$

Previous ACLR is a predisposing factor for subsequent ACL reinjury, ${ }^{7}{ }^{8}$ knee arthritis ${ }^{9}{ }^{10}$ and hamstring (HS) injury in athletes. $^{11} 12$ Debate remains over which surgical procedure for ACLR is superior
Summary box

Hamstring muscle activation patterns during running on a treadmill are different for anterior cruciate ligament (ACL) reconstructed patients having undergone hamstring compared to patellar tendon grafts.

- Peak medial hamstring activation during the stance phase is markedly reduced in comparison to swing phase (for the hamstring graft patients).

- These findings may influence rehabilitation of $\mathrm{ACL}$ reconstruction athletes with the aim to prevent hamstring injuries, or secondary knee joint problems.

in terms of functional and other outcomes despite a large body of research from high level studies. ${ }^{413}$ Commonly ACLR is performed using either autologous bonepatellar tendon bone (BTB) or HS grafts.

The medial HSs are a synergist for the ACL providing a restraining force to anterior translation and lateral rotation of the tibia. ${ }^{14}{ }^{15}$ The lateral HS can off-load the ACL as antagonists to medial rotation of the tibia. ${ }^{16}$ Previous work suggests that HS muscle activation during the jumping and the Nordic HS exercise may not normalise for up to 6 years after ACLR $^{17} 18$ and that restoration of HS muscular activation can be influenced by graft type (HS graft or a BTB graft) ${ }^{19}$ Limited information exists regarding motor patterns of ACLR subjects during running ${ }^{20}$ but we have described different HS activation patterns between prefoot and postfoot contact in a healthy population under different loading conditions. ${ }^{21}$ HS muscle injuries appear most likely to happen at the late swing phase of running, yet are plausible during stance phase. ${ }^{22} 23 \mathrm{~A}$ role of the HS is to act as agonists for the anterior cruciate ligament ${ }^{24}$ but mechanism of activation in these phases after ACLR during the running is unclear. Therefore, we aim to compare HS activation in HS and BTB ACLR patients during treadmill running who have cleared return to sport criteria and, compare these findings to healthy athletes. 


\section{METHODS}

This study examined summation of electrical potentials created by depolarisation of sarcolemma (muscle fibre excitation $)^{25}$ by means of wireless surface electromyography (EMG) signals (hereafter termed 'muscle activation') of the medial and lateral HS of both legs during different treadmill running speeds for a cohort of ACLR subjects ('patient') and a comparison cohort of active healthy male adults ('comparison').

\section{Patient group}

Twenty-one male participants who underwent an isolated ACLR either with either BTB or HS graft were included in the study. All patients participated in pivoting sports and were all at level 9 or 10 on the Tegner scale. The athletes had completed all clinical criteria $(<10 \%$ deficit on Isokinetic and functional field testing, pain-free, no swelling on swipe test and full $\mathrm{ROM}^{6}$ allowing resumption of high speed running. The patient group included patients that underwent an HS $(n=12$, age $26 \pm 3.84$ years, weight $74.16 \pm 7.19 \mathrm{~kg}$ and height $176.89 \pm 5.6 \mathrm{~cm})$ and BTB reconstruction $(\mathrm{n}=9$, age $27 \pm 7.69$ years, weight $80.40 \pm 9.44 \mathrm{~kg}$, and height: $178.49 \pm 7.29 \mathrm{~cm}$ ) and were $5-9$ months, postsurgery.

\section{Comparison group}

Nineteen injury-free male runners (age $35.4 \pm 7.8$ years, weight $77.6 \pm 8.4 \mathrm{~kg}$, height $179.1 \pm 5.6 \mathrm{~cm})$.

Informed consent was obtained for each volunteer participant.

Muscle activation (EMG) from two muscles on both legs Semitendinosus ('medial HS') and Biceps Femoris ('lateral HS') were recorded at $2000 \mathrm{~Hz}$ using a Delsys Trigno Wireless System (Boston, Massachusetts, USA), with electrodes placed following the seniam.org guidelines. ${ }^{2125}$ The EMG signal was filtered using a fourth-order band-pass filter, with low pass cut at $30 \mathrm{~Hz}$ using Matlab (R2014a, The Mathworks, Natick, Massachusetts, USA). A 3 dimensional accelerometer was placed on the shin to identify foot contact and toe-off based on the shank vertical acceleration. ${ }^{21} 2627$

Each step was extracted and normalised from foot contact to foot contact leading to 100 separate time points $(1 \%-100 \%)$. It is reported that HSs show two activation peaks during running, ${ }^{28}$ one in late swing, one during the stance. Instead of considering only a single peak of activation across the entire gait cycle, more information can be gathered by considering these peaks independently. Specifically, the late swing peak appears implicated in high-speed running HS injury. ${ }^{22}$ Conversely, non-contact ACL injury can only happen during stance. ${ }^{29}{ }^{30}$ Accordingly we sought to document both these peaks on either side of foot contact and did so by splitting our data from running trials into 'swing' and 'stance' phases.

HS activation levels show increased amplitude as well as increased variability with increasing speed. ${ }^{31-33}$ To better represent running loads likely encountered during normal training, we examined three treadmill running

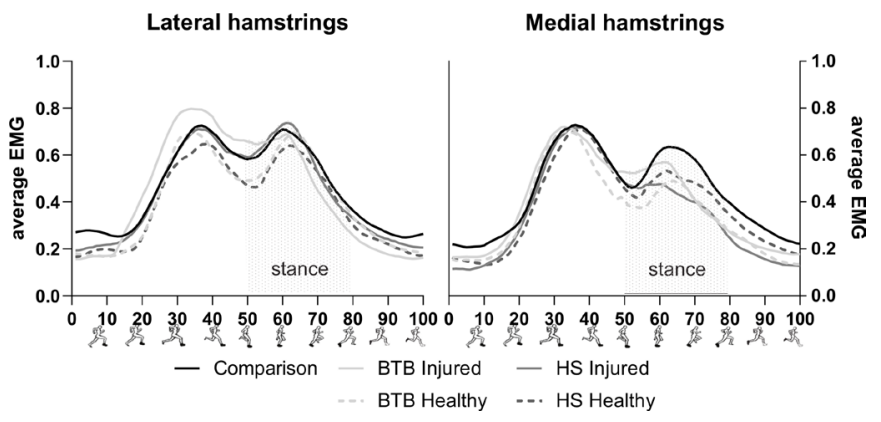

Figure 1 Average EMG activation (y-axis) across the entire gait cycle (x-axis). Note the double peak pattern for both medial and lateral hamstrings (HS) with larger reductions in activation during stance phase for the medial HS compared with comparable activation in both phases for lateral HS. Foot strike occurred at $50 \%$ of the gait cycle (by definition) and toe-off occurred at $79.4 \% \pm 2.9 \%$ of the gait cycle. BTB, bone-patellar tendon-bone; EMG, electromyography.

speed trials $(12,14$, and $16 \mathrm{~km} /$ hour) which reflect moderately fast running likely encountered during higher volume running the athletes would perform during their training. Athletes ran at the selected trial speed until they felt their gait was 'normal' and then 30 s of data collection was commenced. The running speeds were presented in random order. Data from all of these strides (maximum 30) for each subject, for each leg, were individually averaged for subsequent analysis. The peak EMG value as well as the integrated EMG (iEMG) ie, area under the curve in swing and stance phases was identified for each running trial, for each subject. The signal was then normalised to its respective highest value obtained during all the running trials for the individual subject. ${ }^{34}$

To describe the comparison between swing and stance phases for the medial and lateral HS muscles the activation across all three speeds (12, 14 and $16 \mathrm{~km} /$ hour) were pooled to reflect 'typical' activation during moderate to high intensity running training likely encountered in football ${ }^{35}$ (figure 1).

\section{Data processing and statistical analysis}

Peak and mean EMG intra-group differences were identified (left vs right leg, injured vs uninjured leg) for activation in swing and stance phases of the multimuscle EMG series using paired Hotelling's $\mathrm{T}^{2}$ statistics. The significance level was set to $\mathrm{p}<0.05$

An analysis of variance was conducted considering muscle groups, running phase, subject leg, peak EMG, average EMG (iEMG) and patient categories. Subsequent pairwise comparisons with post hoc correction were made for each muscle group examining prefoot and postfoot contact phases for both iEMG and peak EMG for each patient group and leg.

\section{RESULTS}

For the comparison cohort, no significant differences were found comparing left and right legs so data for both legs were pooled for further analyses. For the 
Table 1 Peak and Integrated EMG values for comparison group and ACLR athletes.

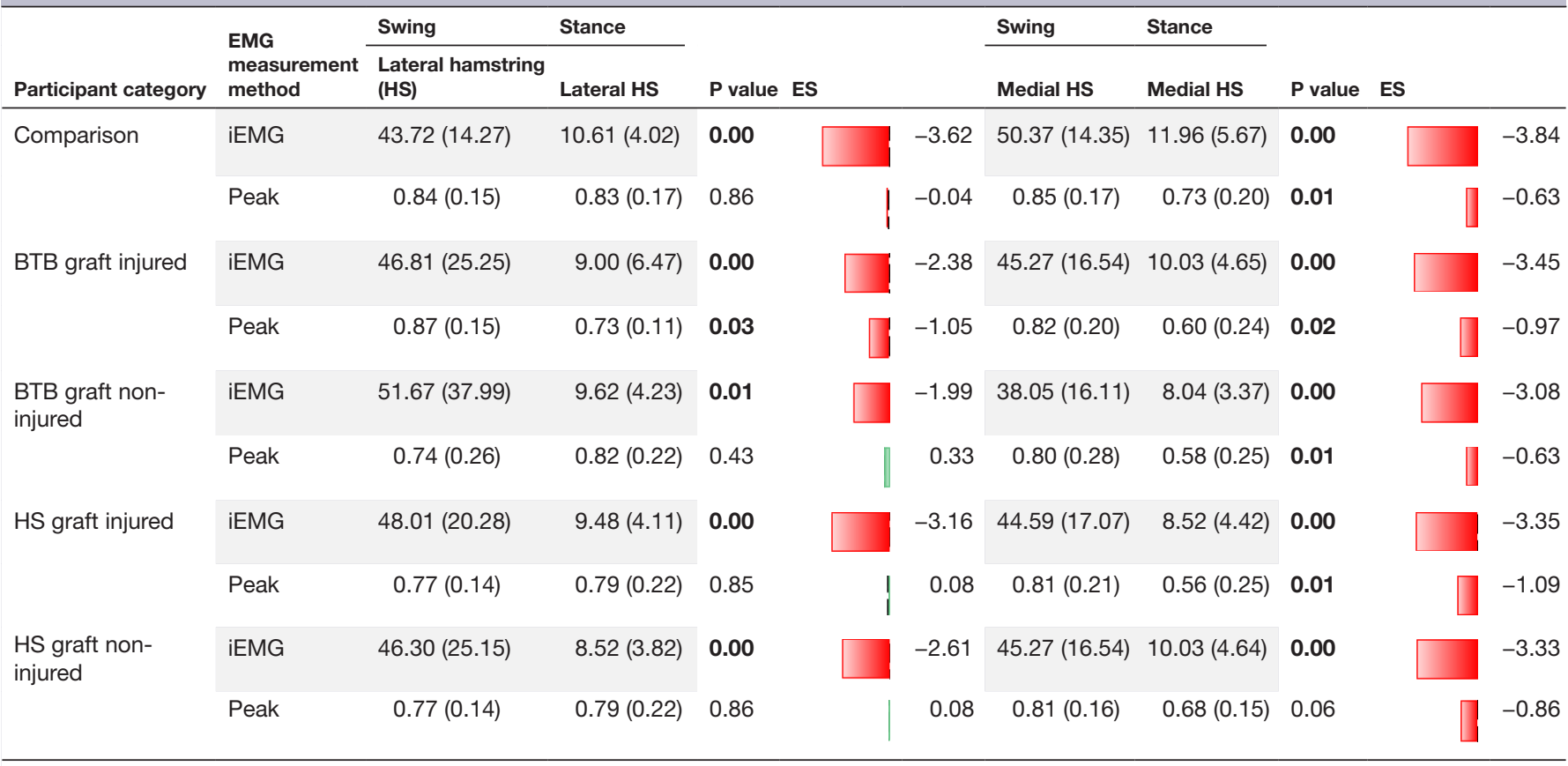

Mean (SD) values and pairwise comparisons for both peak EMG and iEMG for both lateral and medial HS in swing and stance phases for each of the cohorts. Data bars are proportionate representing the magnitude $(E S)$ and direction of the difference in HS activation comparing swing to stance phase. Note that stance phase activation is less than swing phase in 17 out of 20 comparisons, and in all 10 comparisons for the medial HS.

Bold values indicate statistically significant results.

EMG, electromyography; ES, effect size.

patient cohort, data are presented for both their operated ('injured') and uninjured legs. These analyses are summarised for the HS muscle pairs in table 1. Across all participants and conditions, stance phase occurred from $50 \%$ (by definition) to an average of $79.4 \% \pm 2.9 \%$ of the gait cycle.

When comparing the activation during swing and stance phases for the lateral HS, significantly lower iEMG (effect sizes (ES): -1.99 to -3.62 ) values were seen in all groups but only peak EMG (ES: -1.05 ) for the stance phase for BTB graft leg, while all other peak EMG conditions showed no significant differences between swing and stance activation. By contrast significantly lower relative iEMG activation in the swing phase for the medial HS was seen for all conditions with IEMG ES ranging from $(-3.08$ to -3.84$)$. For peak activation significantly lower activation was seen in all conditions except for HS non-injured with ES ranging from -0.63 to -1.09 , and the lowest effect in controls and highest in HS graft.

For the medial HS all patient groups showed similar peak activation in swing phase (BTB injured: 0.82, BTB healthy: 0.80 , HS injured: 0.81 , HS healthy: 0.81 ) while comparisons are slightly higher (0.85). All groups show a reduction in medial HS peak activation comparing swing to stance phase (Comparisons: 0.73, BTB injured: 0.60, BTB healthy: 0.58, HS injured: 0.56, HS healthy: 0.68). Figure 1 shows a more consistent peak activation of the lateral HS in swing (comparisons: 0.84, BTB healthy: 0.82 , HS injured: 0.77 , HS healthy: 0.77) and stance (comparisons: 0.83, BTB healthy: 0.74, HS injured: 0.79, HS healthy: 0.79) with the exception of BTB injured leg where the lateral HS had significantly higher activation in swing (0.87) than stance (0.73) with an associated ES of -1.05 . It is also worth noting that there is a bigger difference in iEMG from swing to stance in medial HS activation than in the lateral HS with ES largest in controls at -3.84 with the lowest of the BTB-injured (ES of -1.99 , table 1 ).

\section{DISCUSSION}

Despite reaching functional clinical goals allowing return to field sport-specific training after ACLR, we report the novel finding of reductions in medial HS activity during stance phase running.

ACLR athletes have higher risk of HS injury, ${ }^{11} 12$ and the data presented here should be of interest in running field sports which also have a high burden from ACL injury (eg, Soccer, Rugby, Gaelic Football, etc). Previous research shows repeated sprinting impairs both strength and neuromuscular activation of the lateral HS. ${ }^{36}{ }^{37}$ We suggest that the alterations in activation post-ACLR found here shed light on the documented association between ACLR and higher risk of HS injury. ${ }^{11} 12$

HS ACLR had both the lowest activation during stance phase and the largest reduction in activation from swing phase to stance phase, with the next largest reduction in the BTB injured group. We speculate that the altered peak medial HS activity in stance phase might be a factor in knee stability potentially leading to laxity ${ }^{48}$ or ACL reinjury. ${ }^{36}$

Differences in neuromuscular strategies during the running after ACLR could be related to loss of sensory 
input from the ACL graft, therefore, preservation of remnant ligament might improve neuromuscular function, ${ }^{39}$ but with no drop in activation during swing phase we speculate that the reduction in activation may begin early postoperative as result of antalgic reduction of activation in donor site HS (during stance phase). Conceivably this learnt behaviour persists during rehabilitation, long after pain has resolved. Patients examined in this study had reached functional return to sport criteria, ${ }^{6}$ however, varied in time taken (5-9 months). The present study is not powered to examine effect of time after surgery, however, muscle activation differences have been reported 1-2 years post-ACLR in functional movements. ${ }^{23}{ }^{25}$ Future research could examine whether restoration of such differences is a function of time (reflecting tissue healing, ${ }^{40}$ especially for $\mathrm{HS}$ graft $^{41}$ ) or functional criteria (reflecting restoration of motor control).

There are limitations to the study. We acknowledge that kinematic or kinetic differences likely exist in addition to the activation patterns described, and that contribution from other synergist muscles working through gait cycle might explain differences in HS activation. Future research should investigate kinematics, kinetics, and activation of more muscle groups. Future research should investigate faster running speeds and direction change to better document motor performance deficits during match situations.

\section{Conclusion}

When running at moderately high speeds $(12,14$, and $16 \mathrm{~km} /$ hour) subgroups of ACLR patients show neuromuscular alterations despite reaching functional goals required for return to training. Lower medial HS activation in the stance phase of running is present in both BTB and especially HS graft patients. These findings might have important implications for both ongoing knee instability and increased HS muscle injury on resumption of sport.

\section{Twitter Athol Thomson @AtholThomson and CLint Hansen @DrClintHansen}

Acknowledgements The authors express appreciation to everyone participating in this study. Special thanks and gratitude to the ACL rehabilitation group of Aspetar Sport Medicine hospital Doha Qatar for the assistance in patient recruitment.

Contributors All authors were fully involved in the study and preparation of manuscript.

Funding Qatar National Library funds the publication.

Competing interests None declared.

Patient consent for publication Not required.

Ethics approval The experiment was conducted with the approval of the local ethics committee (ASPETAR: F2013000001).

Provenance and peer review Not commissioned; externally peer reviewed.

Open access This is an open access article distributed in accordance with the Creative Commons Attribution Non Commercial (CC BY-NC 4.0) license, which permits others to distribute, remix, adapt, build upon this work non-commercially, and license their derivative works on different terms, provided the original work is properly cited, appropriate credit is given, any changes made indicated, and the use is non-commercial. See: http://creativecommons.org/licenses/by-nc/4.0/.
ORCID iDs

Einar Einarsson http://orcid.org/0000-0001-8869-6812

CLint Hansen http://orcid.org/0000-0003-4813-3868

\section{REFERENCES}

1 Lai CCH, Ardern CL, Feller JA, et al. Eighty-three per cent of elite athletes return to preinjury sport after anterior cruciate ligament reconstruction: a systematic review with meta-analysis of return to sport rates, graft rupture rates and performance outcomes. $\mathrm{Br} \mathrm{J}$ Sports Med 2018:52:128-38.

2 Waldén M, Hägglund M, Magnusson H, et al. ACL injuries in men's professional football: a 15-year prospective study on time trends and return-to-play rates reveals only $65 \%$ of players still play at the top level 3 years after ACL rupture. Br J Sports Med 2016;50:744-50.

3 Gifstad T, Foss OA, Engebretsen L, et al. Lower risk of revision with patellar tendon autografts compared with hamstring autografts: a registry study based on 45,998 primary ACL reconstructions in Scandinavia. Am J Sports Med 2014:42:2319-28.

4 Samuelsen BT, Webster KE, Johnson NR, et al. Hamstring autograft versus patellar tendon autograft for $A C L$ reconstruction: is there a difference in graft failure rate? A meta-analysis of 47,613 patients. Clin Orthop Relat Res 2017;475:2459-68.

5 Kamath GV, Murphy T, Creighton RA, et al. Anterior cruciate ligament injury, return to play, and Reinjury in the elite collegiate athlete: analysis of an NCAA division I cohort. Am J Sports Med 2014:42:1638-43.

6 Kyritsis P, Bahr R, Landreau P, et al. Likelihood of ACL graft rupture: not meeting six clinical discharge criteria before return to sport is associated with a four times greater risk of rupture. Br J Sports Med 2016;50:bjsports-2015-095908:946-51.

7 Smith HC, Vacek P, Johnson RJ, et al. Risk factors for anterior cruciate ligament injury: a review of the literature-part 2: hormonal, genetic, cognitive function, previous injury, and extrinsic risk factors. Sports Health 2012;4:155-61.

8 Brophy $\mathrm{RH}$, Schmitz L, Wright RW. Return to play and future ACL injury risk following $A C L$ reconstruction in soccer athletes from the moon group. Am J Sports Med 2012;40:2517-22.

9 Luc B, Gribble PA, Pietrosimone BG. Osteoarthritis prevalence following anterior cruciate ligament reconstruction: a systematic review and numbers-needed-to-treat analysis. J Athl Train 2014;49:806-19.

10 Wang L-J, Zeng N, Yan Z-P, et al. Post-Traumatic osteoarthritis following ACL injury. Arthritis Res Ther 2020;22:57.

11 de Visser HM, Reijman M, Heijboer MP, et al. Risk factors of recurrent hamstring injuries: a systematic review. Br J Sports Med 2012;46:124-30.

12 Verrall GM, Slavotinek JP, Barnes PG, et al. Clinical risk factors for hamstring muscle strain injury: a prospective study with correlation of injury by magnetic resonance imaging. $\mathrm{Br} J$ Sports Med 2001;35:435-9.

13 Mohtadi NG, Chan DS, Dainty KN, et al. Patellar tendon versus hamstring tendon autograft for anterior cruciate ligament rupture in adults. Cochrane Database Syst Rev 2011;9:CD005960.

14 Markolf KL, O'Neill G, Jackson SR, et al. Effects of applied quadriceps and hamstrings muscle loads on forces in the anterior and posterior cruciate ligaments. Am J Sports Med 2004;32:1144-9.

15 Withrow TJ, Huston LJ, Wojtys EM, et al. Effect of varying hamstring tension on anterior cruciate ligament strain during in vitro impulsive knee flexion and compression loading. J Bone Joint Surg Am 2008;90:815-23.

16 Guelich DR, Xu D, Koh JL, et al. Different roles of the medial and lateral hamstrings in unloading the anterior cruciate ligament. Knee 2016;23:97-101.

17 Kasović M, Mejovšek M, Matković B, et al. Electromyographic analysis of the knee using fixed-activation threshold after anterior cruciate ligament reconstruction. Int Orthop 2011;35:681-7.

18 Messer DJ, Shield AJ, Williams MD, et al. Hamstring muscle activation and morphology are significantly altered 1-6 years after anterior cruciate ligament reconstruction with semitendinosus graft. Knee Surg Sports Traumatol Arthrosc 2020;28:733-741.

19 Arundale AJH, Lapham K, Silvers HJ, et al. Medial and lateral hamstring muscle activity differs for ACL graft types. Orthop $\mathrm{J}$ Sports Med 2015;3:2325967115S00103

20 Gokeler A, Benjaminse A, van Eck CF, et al. Return of normal gait as an outcome measurement in ACL reconstructed patients. A systematic review. Int J Sports Phys Ther 2013;8:441-51.

21 Hansen C, Einarson E, Thomson A, et al. Peak medial (but not lateral) hamstring activity is significantly lower during stance phase 
of running. An EMG investigation using a reduced gravity treadmill. Gait Posture 2017;57:7-10.

22 Kenneally-Dabrowski CJB, Brown NAT, Lai AKM, et al. Late swing or early stance? A narrative review of hamstring injury mechanisms during high-speed running. Scand J Med Sci Sports 2019;29:1083-91.

23 Orchard JW. Hamstrings are most susceptible to injury during the early stance phase of sprinting. Br J Sports Med 2012;46:88-9.

24 MacWilliams BA, Wilson DR, DesJardins JD, et al. Hamstrings cocontraction reduces internal rotation, anterior translation, and anterior cruciate ligament load in weight-bearing flexion. $J$ Orthop Res 1999;17:817-22.

25 Hermens HJ, Freriks B, Disselhorst-Klug C, et al. Development of recommendations for SEMG sensors and sensor placement procedures. J Electromyogr Kinesiol 2000;10:361-74.

26 Jasiewicz JM, Allum JHJ, Middleton JW, et al. Gait event detection using linear accelerometers or angular velocity transducers in able-bodied and spinal-cord injured individuals. Gait Posture 2006;24:502-9.

27 Benson LC, Clermont CA, Watari R, et al. Automated AccelerometerBased gait event detection during multiple running conditions. Sensors 2019;19. doi:10.3390/s19071483. [Epub ahead of print: 27 Mar 2019].

28 Howard RM, Conway R, Harrison AJ. Muscle activity in sprinting: a review. Sports Biomech 2018;17:1-17.

29 Waldén M, Krosshaug T, Bjørneboe J, et al. Three distinct mechanisms predominate in non-contact anterior cruciate ligament injuries in male professional football players: a systematic video analysis of 39 cases. Br J Sports Med 2015;49:1452-60.

30 Faunø P, Wulff Jakobsen B. Mechanism of anterior cruciate ligament injuries in soccer. Int J Sports Med 2006;27:75-9.

31 Kyröläinen H, Avela J, Komi PV. Changes in muscle activity with increasing running speed. J Sports Sci 2005;23:1101-9.
32 Higashihara A, Ono T, Kubota J, et al. Functional differences in the activity of the hamstring muscles with increasing running speed. $J$ Sports Sci 2010;28:1085-92.

33 Hansen C, Einarson E, Thomson A, et al. Hamstring and calf muscle activation as a function of bodyweight support during treadmill running in ACL reconstructed athletes. Gait Posture 2017;58:154-8.

34 Ball N, Scurr J. Electromyography normalization methods for high-velocity muscle actions: review and recommendations. J Appl Biomech 2013;29:600-8.

35 Suarez-Arrones L, Torreño N, Requena B, et al. Match-play activity profile in professional soccer players during official games and the relationship between external and internal load. J Sports Med Phys Fitness 2015:55:1417-22.

36 Opar DA, Serpell BG. Is there a potential relationship between prior hamstring strain injury and increased risk for future anterior cruciate ligament injury? Arch Phys Med Rehabil 2014;95:401-5.

37 Timmins RG, Opar DA, Williams MD, et al. Reduced biceps femoris myoelectrical activity influences eccentric knee flexor weakness after repeat sprint running. Scand J Med Sci Sports 2014;24:e299-305.

38 Magnussen RA, Reinke EK, Huston LJ, et al. Effect of high-grade preoperative knee laxity on anterior cruciate ligament reconstruction outcomes. Am J Sports Med 2016;44:3077-82.

39 Ahn JH, Lee SH. Risk factors for knee instability after anterior cruciate ligament reconstruction. Knee Surg Sports Traumatol Arthrosc 2016;24:2936-42.

40 Janssen RPA, Scheffler SU. Intra-Articular remodelling of hamstring tendon grafts after anterior cruciate ligament reconstruction. Knee Surg Sports Traumatol Arthrosc 2014;22:2102-8.

41 Pauzenberger L, Syré S, Schurz M. "Ligamentization" in hamstring tendon grafts after anterior cruciate ligament reconstruction: a systematic review of the literature and a glimpse into the future. Arthroscopy 2013;29:1712-21. 